\title{
Discussion on Effective Optimization of Foreign Language Teaching Interaction under Network Environment
}

\author{
Zhaoxi Wei \\ Beijing Information Technology College \\ Beijing, China
}

\author{
Gang Ji \\ Beijing Information Technology College \\ Beijing, China
}

\begin{abstract}
For the implementation of effective optimization of foreign language teaching interaction under network environment, the "interactive teaching" concept under network environment needs to be optimized, and we shall optimize the supervision by teachers in learning process interaction, optimize teachers' regulatory function under their leading role, as well as optimize network resource to be effective teaching resources.
\end{abstract}

Keywords-network environment; interaction; effective; optimize

\section{INTRODUCTION}

The teaching methods based on information technology and network integration praises fragmented integration of learning content, emphasizing the design optimization of teaching content, supporting the interaction between behavior subject and behavior object of teaching and learning, and encouraging experience and participation. Therefore, in order to achieve the effective teaching under network environment, the interactive concept under network environment needs to be optimized constantly, to optimize relevant links of teaching interaction under network environment.

\section{OPtimization OF "INTERACTIVE TEACHING" CONCEPT UNDER NETWORK ENVIRONMENT}

In the conventional sense, interaction refers to the multidirectional and multi-channel communication and application between teachers and students, students and students, teaching resources and teachers and students in teaching process. However, the interaction under network environment focuses more on informal learning styles under the guidance of technology, namely, the language application under informal learning styles such as information exchange, topic discussion and content sharing using mobile phones, tablet PCs, notebook computers and other mobile terminals. The knowledge will be passed to and penetrated into learner through non-teaching social interactions, such as learning by doing, learning by playing and learning by games. Therefore, informal learning has the basic characteristics of spontaneous, self-control, flexible, social and situational.

This paper is the phased and research-oriented achievement of established projects of Beijing education and teaching reform in 2015 (Project No.: 2015-ms217); the phased achievement of foreign language teaching practice research based on network in 2014 by Commission of Teaching Instruction of Ministry of Education (Project No.: GZGZ5414-57).
At the same time, effective interaction is closely related to substantive learning. With the development of the Internet, especially the development of email and chatting with characteristics of exchange and sharing, as well as forums based on Internet and other technologies, people are in the unprecedented and more diversified and frequent interaction opportunities, but not all interactions under network environment can affect or promote learning, for example, in the interactions of meaningless chatter, surfing the Internet, clicking web pages aimlessly, cannot lead to substantive learning and effective learning effect. Therefore, meaningful interactions shall not only share personal points of view, but also shall stimulate the learners' cognitive interest, make them participate in the effective teaching activities, and affect their learning effect directly. As a result, it is of vital importance to promote substantive learning and the teaching design with meaningful interaction under network environment.

\section{OPTIMIZATION OF TEACHERS' SUPER VISION IN INTERACTIVE LEARNING PROCESS}

Learning process supervision under network environment refers to check students' learning situations at any time and offer the fuzzy comprehensive evaluation around learning requirements of each stage. Supervision can be conducted from such three modules as learning content, learning effectiveness, learning activity and interaction. Learning content: At the time of students' login on the Internet, the specific time of their login, duration, learning situation, login times, students' network autonomous learning notes and other information are recorded in their electronic portfolio. Teachers can open the electronic portfolio from the teaching management access, to learn about students' learning process and effort level, and make suggestions in a timely manner against the existing problems, thus to supervise and urge them to learn actively. In the process of supervising students' learning content, teachers should focus on their learning effectiveness, and achieve the supervision on students' completion of learning objective through analyzing students' completion of their network tasks and their diagnostic test results. As for the supervision of learning activity and interaction, teachers can complete them through various interactive platforms set up in the network platform. For example, learn about students' learning activity and interaction 
through the times of their presentations and participation frequency in course discussion section and group discussion section; learn about students' active learning parameters and degree of knowledge grasping through the communication between students and teachers in the module of communication between teacher and students.

\section{OPTIMIZATION OF REGULATORY FUNCTION UNDER TEACHERS' LEADING ROLE}

Teacher-directed do not mean teacher-dominated. In the current English classroom teaching, teachers still regard themselves as the main controller of the classroom, controlling the teaching content and teaching process too much, without creating sufficient opportunities for students' practice and expression. Therefore, network environment requires teachers to learn about and grasp where and how to use technology as well as which technology shall be used and which learning objective shall be achieved using by virtue of the technology. For this purpose, teachers can restructure learning resources by selecting software, customize or make the learning resources by themselves, to meet students' needs, or enable students to create learning environment using the learning system based on network or mobile terminal for language application.

\section{OPTIMIZE NETWORK RESOURCES INTO EFFECTIVE TEACHING RESOURCES}

Currently, the teaching resources under network environment are mostly the videos, demonstration courseware, and reading materials from network used by teachers in large amount, and regard these ways as language application purpose of learning resources. But due to unable to promote effective language output, they still cause students' low participation in class, few opportunities of language learning and application, thus the effective interaction effect cannot be achieved. Therefore, the teaching resource under network environment shall be the teaching resources with the characteristics of practical and easy to use supporting interpersonal communication processed by teachers on the premise of teachers' learning about students, correct positioning of teaching objective and grasping of learning process. For this purpose, we need:

1) Design learning tasks list. Network resources (micro class, teaching material), should regard learning task list as part of video learning resources, and distribute to students, to help students understand the purpose of watching the video, and confirm the task list to be completed and evaluation methods after watching the video. The task list plays a role of guiding study, enabling students to know what shall be learned, how to learn and what should be done after completion of the learning. Students can also evaluate their own learning effect by comparing with the task list.

2) Implement the principle of relevance. Relevance enables students to appreciate the teachers' attention and supervision. Therefore, teachers can design relevant network resources and teaching content of teaching activities. For example, set up the spot check questions, and carry out a task, encourage students to use knowledge they are learning and understanding to interpret them and so on. The methods and deadline for completing the tasks shall be stressed.

3) Situation design and activity setting, to be convenient for students to express themselves, try to experience and enjoy the application. Diversified activity setting, for example, personal treasure exploration, experiential participation, role playing, yet the group presentation, and the cooperative learning not based on problem and project are not recommended, as they cannot effectively use classroom time to promote improvement and growth of learners. Here, we particularly take the practice of department of foreign languages under 13 Grade network platform as an example. Practice tasks shall be completed in stages, and distribute different work orders based on groups. Students' completion will be followed, feedback and supervised dynamically in real time according to the statistics of work order quantity, quality, speed and effect. By supervising the completion process of work order, diagnostic evaluation and process assessment are realized, which have developed students' teamwork skills, selflearning skills and writing skills as well as skill training under requirements of work order task.

4) Create systematic knowledge. Fragmented learning does not mean scattered knowledge system. We shall use the fragmented time to pay attention to the knowledge that we neglect usually on the premise that certain knowledge system is mastered, to form the knowledge map belonging to themselves, and create many unrelated thinking joints, increase the opportunity of thinking and sudden enlightenment, broaden the original knowledge, make up for deficiencies, to make knowledge systematic and modularized. The knowledge can only be extracted and used correctly and reasonably by put it in definition and classification.

\section{CONCLUSION}

The optimization of effective foreign language teaching interaction under network environment is to create an autonomous and positive learning environment, stimulate the learner's own learning autonomy, arouse their interest in their learning, develop their enthusiasm and sense of participation, as well as learning willpower and self-control ability, thus to obtain a satisfactory learning results and to maintain the state after learning, so that the teaching is more effective, and the learning is of more substantive meaning.

\section{REFERENCES}

[1] Ji Gang, Wei Zhaoxi. Discussion on Optimization of Effective Teaching Interaction Means under Network Environment [J].Science \& Technology Vision, 2015,(33).

[2] Hu Jiewen. Problems in College English Network Autonomous Learning and Countermeasures $[\mathrm{J}]$. Heilongjiang Education:Higher Educational Research and Evaluation, 2015,(11). 